\title{
EVOLUCIÓN HISTÓRICA DE LA LEX MERCATORIA
}

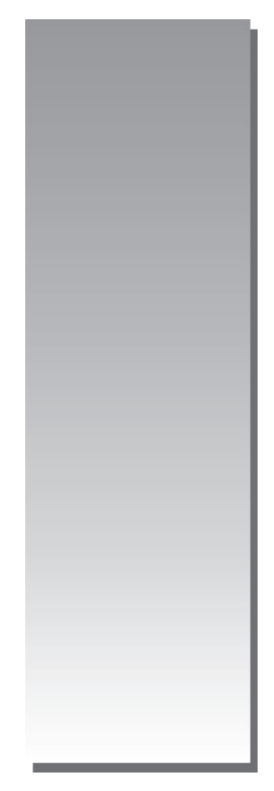

Rose Mary Parra Rivera (*)

E-mail: rosecatedra@hotmail.com

\begin{abstract}
RESUMEN
Se investiga la evolución histórica de un nuevo orden jurídico que regule las transacciones comerciales internacionales mediante la formalización de usos y principios imperantes. Esto es lo que en Derecho Internacional Privado se denomina Lex Mercatoria, que es el derecho surgido de la actividad comercial sin intervención estatal y cuya legitimidad se obtiene por el reconocimiento de los usuarios.
\end{abstract}

Palabras clave: Transacciones comerciales internacionales.

\begin{abstract}
It is investigated the historical evolution of a new juridical order that regulates the internacional business transactions, by means of the formalization of uses and prevailing principles. This is what is named in Private International law, Lex Mercatoria, who is the right arisen from the commercial activity without state intervention, and whose legitimacy is obtained by recognition of the users.
\end{abstract}

Key words: International trading.

(“) Bachiller en Derecho y Ciencia Política por la UNMSM. Abogada por la UNMSM.

Juez Civil de la Subespecialidad Comercial de la Corte Superior de Lima (Poder Judicial del Perú). Docente de la Cátedra de Tratados y Contratos Internacionales de la Facultad de Ciencias Administrativas de la Universidad Nacional Mayor de San Marcos. 


\section{INTRODUCCIÓN}

El Derecho Internacional está en constante evolución y sujeto a muchos cambios, sobre todo el Derecho Mercantil. Así se observa que cada día se realizan grandes esfuerzos para establecer regulaciones que trasciendan a las que podrían denominarse usuales, domésticas o de costumbre. Con tal objetivo, se ha incrementado sustancialmente la firma de diversos acuerdos en foros de gran trascendencia para la humanidad, como las Cumbres de Tokio y Río sobre el Medio Ambiente; los Protocolos de Ginebra sobre Derechos Humanos; la Declaración Universal sobre el Genoma Humano'; el Derecho de Competencia e Integración; el Derecho sobre Propiedad Intelectual; así como otras regulaciones tales como las Convenciones de Viena de 1969 y 1980 sobre el Derecho de los Tratados y sobre las normas de la compra-venta internacional de mercancías.

Los organismos internacionales no son ajenos a esta preocupación por aportar al Derecho Internacional, así tenemos a la Corte Interamericana de Derechos Humanos y al Tribunal Penal Internacional, entre otros. Como puede observarse, la comunidad internacional se muestra muy interesada por instaurar una serie de principios concordantes con la época actual que, sin duda alguna, servirán de marco jurídico para el establecimiento de nuevos tratados internacionales.

Con relación al Derecho Mercantil, la comunidad internacional expresa su preocupación en la búsqueda de un nuevo orden jurídico que regule las transacciones comerciales internacionales basadas en usos y principios imperantes, es decir colaborando en el establecimiento de un derecho surgido de la actividad comercial sin intervención estatal, que es lo que constituye parte del Derecho Internacional Privado; sin embargo, esta preocupación no data de época reciente, ya en el siglo XVIII el Derecho Inglés tenía como uno de sus aportantes a la Lex Mercatoria, que en la época constituía una serie de costumbres y principios heredados del Medioevo que servían para regular el comercio pero que discordaban de las legislaciones de otros países europeos, los cuales habían modernizado sus legislaciones con casi un siglo de antecedencia. Como es natural, el comercio internacional, por su propia naturaleza y por la diferencia o inexistencia de marcos jurídicos, se hizo bastante difícil por la ausencia de un instrumento regulador de tales transacciones; así, en la antiguiedad, la mayoría de países europeos adoptó el principio de la buena fe (fides ubérrima) por parte de los comerciantes, el cual se encontraba ausente en el derecho inglés.

Como era de esperarse, la historia registra controversias muy celebradas como aquella de la póliza de seguro de Fort Marlbouroug (actualmente Bengkulu), construido por la British East Indian Company, en Sumatra, Indonesia. Se sabía que este fuerte había sido construido para soportar solamente ataques de nativos pero no de los europeos, y además existían testigos de lo dicho. Estando asegurado el fuerte, se produjo un ataque al mismo por parte de los franceses, con los consecuentes daños y perjuicios supuestamente cubiertos por el seguro; sin embargo, hecha la exigencia del cumplimiento del seguro, Mansfield tuvo un pronunciamiento histórico al fallar a favor de la aseguradora, puesto que la compañía de seguros desconocía que el fuerte solo había sido construido para resistir ataques de los nativos; es decir, hizo uso de la fides ubérrima, pues quien más conoce de la naturaleza del objeto asegurado es el propietario y éste no declaró de buena fe las debilidades de dicho fuerte.

Ante la presencia de los tratados internacionales se ha venido discutiendo la posibilidad de que exista un tercer orden jurídico que rija las transacciones comerciales. En dicho afán, los operadores

1 Cadena Afanador, Walter René (2001), p. 102.

2 Según María del Carmen Tovar Gil (2007), el Derecho Mercantil como disciplina autónoma no ha existido siempre; su aparición fue como el Derecho Privado por circunstancias y exigencias históricas. En la época romana no existió como tal, ya que recién en la etapa medieval vemos algunos indicios de él, ello por el surgimiento de los centros de actividad económica y comercio. Siendo así, surge fundamentándose como un derecho creado por los propios comerciantes para regular las relaciones surgidas en el trato comercial, teniendo un carácter doble: profesional y consuetudinario. El primero nace de las actividades de los gremios y corporaciones de mercaderes que surgen en la edad medieval, mientras que el segundo carácter nace del hecho que esta regulación es la que los comerciantes adoptan para sus relaciones que se encuentran en los usos y se encuentran al margen del derecho común, dada como una solución adecuada a sus especiales necesidades y finalidades económicas. Así se determina que el Derecho Mercantil nace como un derecho dinámico y flexible nacido de la vida práctica. En consecuencia, se puede decir que el Derecho Mercantil no nace de la fuerza de la ley, sino de la fuerza del uso y costumbres de los comerciantes. En el Perú se denomina Derecho Comercial. 
del comercio internacional se han permitido construir un conjunto de principios y usos mercantiles que debían ser plasmados en los diversos campos del Derecho Comercial Internacional a fin de resolver, de alguna manera, los conflictos de leyes dentro del Derecho Mercantil ${ }^{2}$ e incluso del Derecho Contractual, buscando respuesta a ello con la armonización del Derecho Internacional, ya que la diversidad de normas estatales ha generado y genera una serie de obstáculos para el tráfico internacional.

En la actualidad, el intercambio transfronterizo de bienes y servicios demanda una normativa supranacional que se ajuste a las necesidades de las operaciones del tráfico globalizado; en tal sentido, la globalización del derecho plantea un nuevo estilo de derecho, que tenga como finalidad principal que el Derecho Internacional funcione de una manera diferente al modelo del Derecho Nacional que, en nuestro caso en particular, se basa en el sistema keynesiano y positivista.

Es así que en busca de una respuesta a dichas necesidades se ha construido toda una doctrina en base al derecho pero surgida de la actividad comercial y sin contar con intervención estatal, donde la práctica de los operadores del comercio internacional construye un conjunto de principios y usos mercantiles que se plasman en la contratación internacional, generándose así lo que genéricamente se denomina como jus gentium mercatorum, lex contractus, o lex mercatoria, que viene desempeñando una función conformadora del derecho material uniforme bajo la forma de condiciones generales que se articulan para un determinado contrato internacional.

La Lex Mercatoria en su expresión genuina y latina $^{3}$-concepto que se inicia en la edad media y que está vigente hasta la actualidad- cobra una importancia y extrema relevancia para el Derecho Internacional Comercial hoy en día. La denominación surgió en el plano doctrinal, debido principalmente a Clive Schimitthoff y Berthold Goldman, juristas que denominaron Nueva Lex Mercatoria al conjunto de normas conformadas por principios generales, codificaciones profesionales, contratos típicos y jurisprudencia arbitral, que se dan a través de las organizaciones profesionales, como respuesta a las necesidades del comercio internacional ${ }^{4}$.

\section{EVOLUCIÓN HISTÓRICA}

Como se indicó inicialmente, la Lex Mercatoria como concepto jurídico, evoluciona a través de la historia paralelamente al desarrollo del comercio en la humanidad, ya que el Derecho Comercial propiamente dicho no puede igualarse al devenir histórico de esa rama del derecho con la evolución que sufrió la Lex Mercatoria, pese a que en muchas de sus etapas se afecta directamente su evolución.

\section{1. Época primitiva}

El hombre primitivo se desarrolló en tres aspectos fundamentales: cuerpo, inteligencia y organización social. De las dos primeras facetas se conservan pruebas tangibles, en su mayoría vinculadas a cómo evolucionaron; sin embargo, de la tercera faceta solo puede hacerse un análisis de modo indirecto, realizándolo por medio de analogías, observando lo que sucede en los modernos grupos primitivos y entre animales evolucionados.

Los primeros aspectos jurídicos de la vida primitiva son los referentes a las costumbres relacionadas con la convivencia sexual y, ligados a ellas, la jerarquía dentro del grupo de los que conviven sedentariamente o que forman parte del mismo grupo nómade. La transición hacia la agricultura -esto es, hacia el sedentarismoobliga al hombre primitivo a formar comunidades en las que la ayuda mutua permite vencer la resistencia de la naturaleza; es así como surgen las ideas jurídicas de propiedad y posesión. Con el paso del tiempo, las comunidades primitivas se convierten en países y de las luchas de los diversos países surgen esclavos y amos, esto es, la estratificación social, al mismo tiempo que el Derecho Internacional. Por ello, debemos indicar que, al inicio, el ser humano se proporcionaba lo necesario para su subsistencia, buscando satisfacer el consumo personal y el de su familia mediante actividades como la caza y recolección, esto dado por el hecho de ser nómade. Se infiere que con dichas actividades realizaron algo muy parecido a un trueque, y por el intercambio de

3 "In others words, there is a growing sense that the lex mercatoria is not merely an English-Language 'Law Merchant', assuming that global private law is possible, global law expressed only in English is not global law”. Ver Kasirer, Nicholas. (1999), pp. 653-654.

4 Tovar Gil, María del Carmen. (2007). Op. cit., p. 106. 
productos pudo darse inicio al comercio pero de modo bastante incipiente.

Las actividades de caza y recolección, al ir evolucionando hacia la siembra de productos o al aprovechamiento del medio, produjeron que unos quisieran lo que producía el otro, naciendo así el canje de productos o mercaderías, estableciéndose en esta etapa primaria que las actividades del hombre no se podían incluir dentro del estructurado Derecho Comercial, como actualmente se determina ${ }^{5}$.

\section{2. Época Antigua}

Dentro de esta etapa, el comercio como fenómeno económico y social se presenta en los pueblos más antiguos. Pueden encontrarse normas aplicables al comercio, o más bien a alguna de las instituciones ligadas a aquella actividad de origen; sin embargo, en los sistemas jurídicos de los pueblos más antiguos, como Babilonia, Egipto, Grecia, Fenicia y Cartago, podemos encontrar gérmenes remotos del Derecho Mercantil en normas aisladas, sin que ello signifique que haya existido un derecho especial o autónomo propio de la materia mercantil.

\section{a. En Egipto}

La historia del comercio muestra que los egipcios nunca fueron un pueblo de comerciantes. Al estar dedicados fundamentalmente a la agricultura, el comercio marítimo estuvo en manos de extranjeros. Los antiguos egipcios, a pesar de utilizar en gran escala los metales, no usaron moneda sino hasta la llegada del conquistador Alejandro al delta del Nilo; no obstante lo anterior, y considerándose que dependían fundamentalmente del trueque, se dice que tenían un sistema notablemente adelantado de crédito y contabilidad.

\section{b. En Babilonia}

Los reyes, empezando por el propio Hammurabi, estimulaban la actividad mercantil con la regulación del curso de los ríos, la constitución de nuevos canales y el fomento de la construcción de barcos. El Código de Hammurabi debe ser visto en su época sobre un contexto de muchos pueblos antiquísimos y otros recién incluidos en la órbita de la vida civilizada; también debe considerársele en el marco de una sociedad abigarrada, la cual estaba corrompida por la guerra y las deportaciones en masa, así como las rivalidades del poder, dispuesta a sacar beneficio de toda circunstancia. A continuación indicaremos dos normas del Código de Hammurabi: Si una persona compra plata, oro, un sirviente, un buey, una oveja, un asno, al hijo de otro, o a un esclavo, o los recibe en depósito, sin testigos y documentos, ha procedido como un ladrón y será condenado a muerte". La segundo norma indicaba: "Si un barquero alquilare un barco y navegare con el sin cuidado y lo embarrancase o perdiese, le dará otro igual al propietario.

En la época neobabilónica, la formulación legal está a veces concebida en términos muy generales. El contrato de sociedad se hace a veces por corto tiempo, pero en otras situaciones sus operaciones abarcan algunos años, durante los cuales se hace de vez en cuando un arreglo provisional.

\section{c. En Persia}

Los persas fueron, de algún modo, herederos del comercio mesopotámico, y en la historia no se hace mención a ninguna codificación específica. Lo mismo ocurre tratándose de los fenicios, cuya historia mercantil es de gran interés. Así, podríamos señalar que los grandes imperios del Antiguo Oriente (babilonios, asirios, egipcios y persas) tuvieron un carácter eminentemente continental y militar; ninguno supo explotar las enormes perspectivas económicas que tuvieron ante sí.

\section{d. En Cartago}

Los cartaginenses fueron extraordinarios navegantes y colonizadores. En tal sentido, debemos recordar la famosa expedición dirigida por Hannon, que llegó hasta el Golfo de Guinea, y en España fue fundador de varias colonias, entre ellas Cartagena. Los cartaginenses gobernaban y dominaban políticamente sus colonias. La posición de Sicilia los puso en contacto con Roma, con lo cual se originaron las tres largas guerras púnicas que acabaron con la metrópoli africana.

\section{e. En Fenicia}

Los fenicios, en dicha época, fueron los grandes enemigos comerciales de los griegos. Los fenicios habían establecido factorías en Grecia, especialmente en Creta, Chipre y Beocia. De

5 Guillén Jiménez, Daniel (2008). 
ellos aprendieron los griegos a construir naves $\mathrm{y}$ a navegar, y poco a poco fueron rescatando su propio comercio y al convertirse en el pueblo más comercial del Mediterráneo, arrebatando a los fenicios el suyo.

\section{f. En Grecia}

Es de resaltar que ningún pueblo antiguo realizó, en proporción, tantas emigraciones ni fundó tantas colonias como el griego. Durante la expansión colonial griega, que duró unos seiscientos años, desde el siglo XI al VI a DC., puede decirse que no hubo región en el Mediterráneo que no estuviera colonizada por ellos. Tenían colonias en el Asia Menor, en las orillas del Mar Negro, en Chipre, Creta y en la Galia, donde los focenses fundaron Marsella; también en España, África e Italia. Las que fundaron en las costas meridionales de este último país alcanzaron tan alto grado de prosperidad que fueron llamadas por los propios griegos la Magna Grecia.

Resaltamos la ciudad de Atenas que por su ubicación geográfica tuvo un excepcional desarrollo económico y social, así como político. Dentro de sus medidas y avances resaltantes se pueden citar:

- La unificación de pesos y medidas, y los procedimientos judiciales, además de asegurar el curso del dinero mediante el concurso de banqueros, lo cual contribuyó a que las ciudades formen una clase de mercaderes profesionales que adquieren mentalidad y costumbres cosmopolitas.

- El conocimiento de los derechos que gravaban las mercancías, a los que se consideraban como medidas fiscales.

- Los extranjeros eran libres de ejercer el comercio en Atenas y el estado se abstenía, en principio, de participar en la formación de asociaciones y sociedades.

- En derecho marítimo, el naiticum foenus, era conocido como el precedente del préstamo a la gruesa, y consistía en un préstamo para una exportación por mar, la devolución del cual estaba subordinada a que el buque llegase a buen puerto, en cuyo caso el prestamista percibe-además del capital- unos intereses muy superiores a los ordinarios a título de beneficio marítimo y como precio del riesgo.

- El prestatario quedaba liberado de todo pago en caso de naufragio y, en caso de una pérdida parcial, se liberaba parcialmente de la deuda.

- Se contaba también con la Lex Rodhia, que tiene su origen en una antigua práctica fenicia y que se constituye en el antecedente de la echazón, que ha pasado a los códigos modernos con el nombre de avería común o avería gruesa. El derecho romano adoptó esta institución conocida como Lex Rodhia de jactu.

- Existía una jurisdicción especial de jueces mercaderes, con un procedimiento rápido que debía terminarse en un mes y que no era susceptible de ningún recurso; sin embargo, era corriente que los comerciantes acudieran al arbitraje control, al cual se podía recurrir antes de ir a los tribunales, pero los árbitros podían abstenerse de juzgar y requerir a las partes para que sometieran el asunto a los tribunales ${ }^{6}$.

\section{g. Roma}

Desde sus inicios, Roma tuvo mucha influencia de la cultura griega. Es así como los habitantes de Lacio toman de Grecia la escritura y también la recepción del derecho griego, tal como lo señala Fernando Mora: "Los romanos fueron un pueblo eminentemente agricultor, nacido en el agro para el agro", pudiendo inferirse de ello que el pueblo romano fue un pueblo de agricultores que con posterioridad se convirtió en el centro del comercio mundial de la época, y por ello pudieron lograr una rudimentaria economía dineraria, debido al creciente desarrollo de sus nuevas instituciones jurídicas que fueron surgiendo y, en otros casos, por la transformación de las propias instituciones civiles que ya existían. Sin embargo, debemos tener presente que aun en dicha época no surgió un derecho especial para el comercio distinto y separado del jus civile, ello en razón a que el derecho romano -por ser de naturaleza dinámica y por la existencia de un sistema flexible de aplicación

6 Guillén Jiménez, Daniel. 2008. Op. Cit. 
del derecho por el pretor $^{7}$ y su buen jus civile romano- lo hicieron innecesario ${ }^{8}$.

\section{3. Época Medieval}

Los antecedentes mediatos de la Lex Mercatoria se sitúan en esta época, toda vez que el Derecho Mercantil alcanzó su consolidación desde su surgimiento en el Medioevo. Con ella surgió una clase social: la Societas Mercatorum, la cual se dedicó al comercio, adquiriendo la Societas un poder dentro de la sociedad al implementar una serie de usos y costumbres profesionales que se denominaron Lex Mercatoria. La Societas se encontraba integrada por artesanos y comerciantes, quienes se organizaron mediante corporaciones y gremios que por necesidad y avance de su actividad se tornaron internacionales; de este modo, las normas internas o leyes locales se volvieron inadecuadas para sus requerimientos que implicaban una necesidad de índole internacional. Por tal motivo, se establece que el desarrollo de la Lex Mercatoria se sitúa desde principios del siglo XII hasta mediados del siglo XVI.

La evocación de una genealogía de la Lex Mercatoria puede ser más poderosa que el concepto, ya que invita a menos controversia doctrinal en la corriente principal del discurso; así mismo, proporciona un modelo para el futuro desde que la Lex Mercatoria moderna se presenta en los relatos genealógicos, ya sea como la reencarnación o renacimiento de la antigua ley o como resultado de su evolución.

En la Edad Media las ferias se celebraban anualmente en ambientes que se constituían en campos de producción de la Lex Mercatoria, donde los comerciantes que provenían de distintos lugares asistían a ellas por varias semanas con el aval del rey anfitrión que permitía a los mercaderes arreglar entre ellos sus litigios comerciales. Junto a las ferias se instalaron los gremios y las corporaciones desde mediados del siglo XII, quienes poseían órganos propios de dirección, autonomía normativa y jurisdicción especial para aplicarla. En dicho ambiente se desarrolló un Derecho Mercantil constituido por las costumbres y usos de una clase social caracterizada por una nacionalidad, legitimidad, uniformidad y el uso en un amplio sentido de las aequitas medieval.

En tal sentido se puede indicar con todo acierto que en la época del Medioevo el Derecho Mercantil fue creado y usado por un segmento específico de la sociedad, consolidado como un derecho de clase; es decir, hecho por mercaderes y para mercaderes ${ }^{9}$. El auge del derecho corporativo medieval surgió en Italia pasando a Holanda, Inglaterra, Cataluña y el norte de Alemania.

La Lex Mercatoria se plasmó por escrito no obstante su origen consuetudinario; posteriormente se recogió en estatutos corporativos que a su vez integraron tratados interlocales e internacionales. Se relacionaban continuamente con los demás sistemas legales (feudal, eclesiástico, urbano y real), teniendo en cuenta sus cualidades intrínsecas como la universalidad, la reciprocidad, la objetividad, la particularidad, la integración y el crecimiento. Además, la Lex Mercatoria se caracterizaba por ser cosmopolita basada en flexibilidad, especialidad y autonomía; todo ello -aunado a la inoperatividad del derecho civil medieval- permitió el fortalecimiento de la Lex Mercatoria.

A partir del siglo XV surge la teoría del mercantilismo, así, durante el periodo que abarca desde el siglo XV hasta fines del XVIII, se promulga el Código Civil Napoleónico, influenciado fuertemente por las ideas de la Revolución Francesa, trayendo como consecuencia una mayor importancia del poder político de la economía. Durante este periodo se produce la Revolución Industrial y el Derecho Mercantil tradicional comienza a perder importancia como consecuencia de la expansión de las primeras ordenanzas mercantiles, documentos escritos del Derecho Mercantil.

7 El pretor era el encargado de dictar justicia, era el colega menor de los cónsules, destinado a resolver conflictos entre los ciudadanos romanos. En el año 242 se crea el pretor Peregrinus, el cual tiene como función dictar justicia en los pleitos entre ciudadanos romanos o extranjeros, o entre extranjeros. Su función principal es jurisdiccional: declarar los principios jurídicos a aplicarse en los pleitos y posibilitar la constitución del indicium, es decir la actividad de un iudex, que debe al final, dictar sentencia según los lineamientos fijados por el pretor. Tiene jus edicendi, derecho a publicar edictos al comienzo de su gestión. Grababa en una piedra blanca llamada álbum los ppios o reglas a los cuales se ajustaría su actuación durante el desempeño de la magistratura. El edicto del pretor consta de las siguientes partes: a) una parte introductoria que asegura la obediencia de los ciudadanos; b) una parte central dividida en i) Pars traslaticia: parte de edictos anteriores que creía prudente no innovar; ii) Pars nova: innovaciones introducidas por el pretor y iii) Apéndice.

8 Tovar Gil, María del Carmen (2007), op. cit.

9 Cadena Afanador, Walter René (2001), op. cit. 


\section{Dentro de esas ordenanzas destacan:}

- Ordenanza Francesa del Comercio, promulgada por Luis XIV (1673).

- Ordenanza Francesa de la Marina (1681).

- Ordenanza de la Universidad y Casa de contratación de Bilbao, promulgada por Felipe $\mathrm{V}$ (1737) y confirmada por Fernando VII (1814).

- Ordenanza de Burgos de 1495.

- El Código Napoleónico de 1807, que es un importante paso respecto de las Ordenanzas, siendo que por medio de este Código -y por primera vez- se consigue la sistematización de toda la normativa mercantil en un solo cuerpo legal. Es un código muy influenciado por las ideas de la Revolución Francesa y, gracias a él, se desarrolló la Doctrina Objetiva del Derecho Mercantil: toda actividad considerada comercial es tal con independencia de quien desarrolla tal actividad, teniendo su final con la promulgación del Código de Comercio italiano de 1882, el cual tuvo su antecedente en el Código Alemán de 1861.

La importancia de la Lex Mercatoria decayó en el siglo XVI debido a sus falencias internas por cuanto se había tornado menos transparente, imprescindible e imparcial en su aplicación, acelerando su caída el afianzamiento del derecho bajo el entero manejo del Estado Moderno, el cual absorbió y prohibió la Lex Mercatoria trasnacional. A esto se unió el hecho de que los principales centros comerciales fueron desplazados desde Italia y el norte de Alemania hacia Holanda, Inglaterra y Francia.

Es así que la antigua Lex Mercatoria quedó enteramente nacionalizada a consecuencia del antiguo sistema, desapareciendo los asuntos que -en algún momento- eran tratados de manera expeditiva bajo normas que surgían de la práctica trasnacional, quedando bajo la jurisdicción de tribunales locales. Perdió así su carácter trasnacional, su consistente referencia a la costumbre, su administración ad-hoc, su informal y ágil aplicación, y su énfasis en el concepto medieval de justicia $^{10}$.

\section{Etapa Contemporánea}

Surge a principios del siglo XX, coincidiendo con el desarrollo de la doctrina de la empresa, y finaliza en 1942, año en el cual se promulgó el Código Civil Italiano. La nota más característica es que en esta etapa se configura de forma muy perfeccionada la idea de empresario como profesional que ejecuta una actividad económica de forma continuada.

Desde mediados del siglo XX se ha originado un gran debate respecto de la Lex Mercatoria, el cual va desde su negación hasta su defensa. Es así que la sistematización y valoración de la nueva Lex Mercatoria, dentro de las relaciones comerciales internacionales, está ligada a dos juristas: Clive Schmitthoff y Berthold Goldman. En el caso de Schmitthoff ${ }^{11}$, quien propone una distinción entre costumbre comercial y uso comercial, basada en el criterio de la formalización hecha por un organismo internacional y con un grado de certeza. Es así que llama "costumbre comercial internacional" a la costumbre formulada por un organismo internacional, o al uso o práctica de la costumbre que no ha sido formulada; con ello se permite darle la formulación necesaria a esta nueva norma de carácter anacional, concluyendo el autor germano que la nueva Lex Mercatoria es el inicio de un Derecho Comercial autónomo.

Goldman ${ }^{12}$ observa que la nueva Lex Mercatoria constituye un derecho sustantivo o de fondo aplicable a una relación internacional sin pasar por el filtro del método conflictual. La Lex Mercatoria convoca al conjunto de reglas materiales aptas para gobernar las relaciones económicas internacionales. Ella comporta en su interior fuentes interestatales como son los convenios de leyes uniformes o estatales, así como las sentencias arbitrales que se emiten dentro de relaciones de comercio internacional, siendo así un derecho experimental; es decir, surge interviniendo dentro de la solución de las relaciones económicas internacionales.

Es de remarcar que ambos autores, Schmitthoff y Goldman, coinciden en el hecho que la Lex Mercatoria constituye un sistema de derecho

10 Cadena Afanador, Walter René (2001). Op. cit.

11 Kassis, Antoine (1984), p. 269.

12 Goldman, Berthold (1979), p. 224. 
incompleto, pero en crecimiento dentro de las transacciones privadas internacionales, que lleva a la creación de una norma paralela a la de los estados nacionales y que es construida sobre la base de usos y generalmente desarrollada en sectores de actividades específicas que, por su semejanza con el Derecho Mercantil (Derecho Comercial) de la Edad Media, viene siendo denominada como nueva Lex Mercatoria Internacional ${ }^{13}$.

En conclusión, podemos observar que la Lex Mercatoria es una denominación surgida de la actividad comercial sin intervención estatal y que nació en la Edad Media, época en la que -por regulación incipiente de los Estados y de los Feudos en materia mercantil- los comerciantes se vieron en la necesidad de desarrollar reglas y principios aplicables a sus transacciones, extraídas de los usos y las reglas gremiales, como una suerte de orden jurídico aplicable a las relaciones que surgían entre ellos, denominándose a dicha reglamentación Lex Mercatoria.

Se han desarrollado múltiples debates en torno a este concepto que puede parecer tan etéreo e indefinido, pero como nueva Lex Mercatoria reviste una importancia capital dentro del Derecho Comercial Internacional. Siendo así, actualmente es factible considerar que este es un ordenamiento jurídico autónomo con plena vocación para ser aplicado a una transacción mercantil, sin dejar de expresar que existen muchas críticas y controversias al respecto, ya que se trata de un instrumento en constante evolución.

\section{BIBLIOGRAFÍA}

\section{Libros}

BERCOVITZ RODRÍGUEZ-CANO, ALBERTO (1997). "Origen Histórico del Derecho Mercantil". En: UNIVERSIDAD DE COSTA RICA. (1997). Antología de la Cátedra de Derecho Comercial I. San José de Costa Rica, Universidad de Costa Rica.

BRILLA FERRER, CARLOS EDUARDO (1998). LoS "Orígenes Históricos del Derecho Mercantil Costarricense: de las ordenanzas de Bilbao de 1737 al Código de Comercio de 1853". Tesis para optar el grado de Licenciado en Derecho. San José de Costa Rica, Universidad de Costa Rica.
CABANELLAS, GUILLERMO (2003). Diccionario Enciclopédico de Derecho Usual. Tomo IV. Buenos Aires, Editorial Heliasta.

CADENA AFANADOR, WALTER RENÉ (2001). "La Nueva Lex Mercatoria: Un caso pionero en la globalización del derecho". PONTIFICIA UNIVERSIDAD JAVERIANA. Papel Político. N. ${ }^{\circ}$ 13, octubre del 2001. Madrid, Pontificia Universidad Javeriana.

CHULIA, VICENT F. (1991). Compendio Crítico de Derecho Mercantil. Segunda Edición. Tomo I. Barcelona, José María Bosch.

DE SOLÁ CAÑIZARES, FELIPE (1963). Tratado de Derecho Comercial Comparado. Tomo I. Barcelona, Editorial Montaner y Simón SA.

FAYA RODRÍGUEZ, ALEJANDRO (2004). "La nueva Lex Mercatoria: naturaleza y alcances". En: DEPARTAMENTO DE DERECHO DE LA UNIVERSIDAD IBEROAMERICANA. Jurídica. Anuario del Departamento de Derecho de la Universidad Iberoamericana. $N^{\circ} 34$. España, Sección de Previa.

FELDSTEIN DE CÁRDENAS, SARA (1998). El Arbitraje. Buenos Aires, Abeledo Perrot.

GALGANO, FRANCESCO (1976). Lex Mercatoria. Bologna, Il Mulino.

GOLDMAN, BERTHOLD (1979). "La Lex Mercatoria Dans Les Contrats et L'Arbitrage Internacional". En: DU COMITÉ FRANCAIS DE DROIT INTERNACIONAL PRIVÉ. Droit Internacional Privé. Annés 1977. París, Paris, Juvis-Classeur.

GUILLÉN JIMÉNEZ, DANIEL (año). "Introducción a la Lex Mercatoria". En: Revista Judicial del Poder Judicial de Costa Rica, N. -89 julio. Costa Rica, Editor Poder Judicial de Costa Rica.

KASIRER, NICHOLAS. (1999). "Lex Icographie Mercatoria". En: The American Journal of Comparative Law. Volumen 47, 1999. Chicago, Publisher The American Society of Comparative Law.

KASSIS, ANTOINE (1984). Théorie Génerale Des Usages Du Comerse. París, L.G.D.L.

KONRADI, WIOLETTA y FIX-FIERRRO, HÉCTOR (2006). "La Lex Mercatoria en el espejo de la investigación empírica”. En Boletín Mexicano de Derecho Comparado [en línea] 2006, Vol.

13 Chulia, Vicent F. (1991), p. 45. 
XXXIX [citado 2011-01-19]. Disponible en Internet: http://redalyc.uaemex.mx/redalyc/ src/ArPdRed.jsp.

LABARIEGA VILLANUEVA, PEDRO ALFONSO (1998). "La moderna Lex Mercatoria y el Comercio Internacional". En Revista de Derecho Privado. $\mathrm{N}^{\circ}{ }^{\circ} 26$. Sección de Doctrina, México. Editorial MC Graw-Hill.

MANTILLA MOLINA, ROBERTO (2006). Derecho Mercantil. México, Editorial Porrúa.

MORA, FERNANDO (1991). Introducción al estudio del Derecho Comercial. Segunda Edición. San José, Costa Rica, Editorial Juritexto.

PERENNE, HENRI (1975). Historia Económica y Social de la Edad Media. Madrid, Fondo de Cultura Económica.

PÉREZ VARGAS, VÍCTOR (2005). La Lex Mercatoria, Antología de Derecho de la Contratación Internacional. San José de Costa Rica, Universidad de Costa Rica.

SILVA, JORGE ALBERTO (2006). Estudios sobre Lex Mercatoria. México, Universidad Autónoma de México.
SOLANO PORRAS, JULIÁN (1999). "Lex Mercatoria”. En: Revista Judicial de la Corte Suprema de Justicia de Costa Rica. ‥ ${ }^{\circ} 76$, Costa Rica. Editado por el Poder Judicial de Costa Rica.

TOVAR GIL, MARÍA DEL CARMEN (2007). "Aplicación de la Lex Mercatoria internacional por los árbitros". En: Revista Lima Arbitrión. ․․ 2. Revista del Círculo Peruano de Arbitraje. Lima, Editor General Roger Rubio Guerrero.

URÍA, RODRIGO y MELÉNDEZ, AURELIO (1999). Curso de Derecho Mercantil I. Madrid, Editorial Civitas.

\section{Internet}

CASTROGIOVANI, R.M. (2008). "Lex Mercatoria". En: REVISTA ELECTRÓNICA DE DERECHO COMERCIAL (2008). Compilación Especial. Buenos Aires, Revista Electrónica de Derecho Comercial. Ver en: www.derechocomercial.com 